\title{
Avaliação do uso de resíduo de serragem de pedra Cariri (RSPC) para produção de concretos convencionais
}

\author{
Evaluation of the use of Cariri stone sawing dust in the \\ production of concrete
}

\section{Washington Almeida Moura \\ Mônica Batista Leite Adolfo Jacques Oliveira Bastos}

\section{Resumo

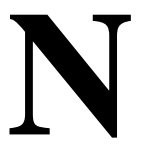

o estado do Ceará, na região do Cariri, um minério calcário laminado, comercialmente conhecido como pedra Cariri, é muito explorado. Os processos de exploração e beneficiamento desse minério são causas da geração de resíduos. Um dos tipos de resíduo gerado é o decorrente da serragem de pedra Cariri, denominado de resíduo de serragem de pedra Cariri (RSPC). Nesta pesquisa, avalia-se a viabilidade do uso de RSPC como substituição parcial do cimento na produção de concretos convencionais. Foram determinadas as características químicas e físicas do RSPC. A influência foi avaliada através das propriedades mecânicas (resistência à compressão axial e diametral) e parâmetros de durabilidade (absorção por imersão e por sucção capilar). Foram produzidos 9 traços, variando a relação a/c $(0,45 ; 0,55 ; 0,65)$ e os teores de substituição $(0 \%, 10 \%$ e $20 \%)$ do cimento. Os resultados demonstram que a utilização de RSPC no concreto proporcionou uma redução nas resistências à compressão e à tração por compressão diametral. Entretanto, em relação aos

Washington Almeida Moura Departamento de Tecnologia Universidade Estadual de Feira de Santana

$\mathrm{Km} 03 \mathrm{Br}$ 116, Campus Universitário Feira de Santana - BA - Brasil CEP 44031-460

Tel.: (75) 3224-8117 Ramal 8357 E-mail: washington.moura@gmail.com

Mônica Batista Leite Laboratórios de Tecnologia, Departamento de Tecnologia Universidade Estadual de Feira de Santana

Av. Transnordestina, $s / n$, Campus Universitário, Novo Horizonte Feira de Santana - BA - Brasil CEP 44036-900 Tel.: (75) 3224-8117

E-mail: mleite.uefs@gmail.com

Adolfo Jacques Oliveira Bastos Instituto de Estudo de Materiais de Contrução

Av. Dr. Guarany, 317, Campus da CIDAO, Derby

Sobral - CE - Brasil CEP 62040-730 Tel.: (88) 3611-6796

E-mail: adolfobastos@hotmail.com

Recebido em 22/03/12 Aceito em 07/02/13 parâmetros de durabilidade, os concretos com RSPC apresentaram comportamento compatível com os concretos de referência. De um modo geral, do ponto de vista técnico, o RSPC não proporcionou resultados satisfatórios para aplicação em concreto.

Palavras-chave: Resíduo de pedra Cariri. Reciclagem. Concreto. Propriedades mecânicas. Durabilidade.

\section{Abstract}

In the state of Ceara, in the Cariri region, a laminated limestone rock, commercially known as Cariri stone, is explored intensively. The exploration and processing of the Cariri stone generates a large amount of waste. One of the types of waste generated is the sawing dust from the cutting process of the Cariri stone, known as Cariri stone sawing dust (CSSD). The aim of this study is to assess the feasibility of using CSSD as partial replacement of cement, by mass, in the production of conventional concrete. The chemical and physical characteristics of the CSSD were determined, as well as the influence of CSSD on the mechanical properties of concrete (compressive strength and splitting tensile strength) and durability parameters (absorption rate and capillary suction). Nine concrete mixtures were produced with varying w/c ratios $(0.45,0.55,0.65)$ and cement replacement levels (0\%, 10\% and 20\%). The results showed that the use of CSSD reduces the parameters of the mechanical properties of concrete. However, no significant influence was found regarding the durability parameters. These results point to the unfeasibility of the use of CSSD in concrete. In general, from a technical point of view, CSSD does not provide satisfactory results for its use in concrete.

Keywords: Cariri Stone Sawing Dust. Recycling. Concrete. Mechanical Properties. Durability. 


\section{Introdução}

$\mathrm{Na}$ região do Cariri, no estado do Ceará, localizam-se os municípios de Nova Olinda e Santana do Cariri, os dois maiores produtores de um calcário laminado conhecido como "pedra Cariri”. A exploração dessa rocha é a principal atividade desses municípios e gera cerca de 1.500 empregos diretos. A produção média é estimada em 80 mil toneladas de pedra Cariri por ano (VIDAL; FERNANDES, 2007). Contudo, a mineração e o beneficiamento da pedra Cariri é uma atividade que gera grandes volumes de diversos tipos de resíduos, entre eles o resíduo de serragem de pedra Cariri (RSPC). Ainda não existem estudos criteriosos da quantidade de RSPC gerado. Todavia, de acordo com Vidal e Fernandes (2007), pode-se estimar que sejam geradas na região do Cariri por volta de 850 toneladas/ano de resíduo.

A construção civil é um dos maiores consumidores de matérias-primas naturais. Estima-se que consome entre $20 \%$ e $50 \%$ de todos os recursos naturais extraídos (SJOSTROM, $1996^{1} 1996$ apud JOHN, 2000). Além disso, o setor é responsável por grande consumo de energia e emissão de poluentes na atmosfera. Segundo Gonçalves, Moura e Leite (2003), para cada tonelada de clínquer produzida é gerada 0,65 tonelada de $\mathrm{CO}_{2}$.

Devido à necessidade de atender ao elevado consumo de materiais por parte da construção civil, esta se apresenta como um potencial agente reciclador de resíduos. A utilização de resíduos na construção civil, além de preservar o meio ambiente, proporcionando uma destinação mais adequada dos resíduos, apresenta-se como uma boa maneira de preservar as reservas naturais de matéria-prima, prolongando, dessa maneira, a vida útil das jazidas.

O concreto, um dos materiais mais usados na construção, pode incorporar subprodutos de indústrias, em substituição ao material aglomerante ou aos agregados, o que contribui para a conservação de recursos naturais e melhoria de seu desempenho quanto ao aspecto de resistência e durabilidade. Em decorrência disso, a utilização de adições no concreto de cimento Portland aumentou consideravelmente nos últimos tempos, proporcionando, além da melhoria do desempenho mecânico e das características de durabilidade, redução nos custos de produção de concreto.

As adições minerais podem apresentar efeito físico (adições do tipo fíler) ou efeito físico e químico

${ }^{1}$ SJOSTROM, C. Service life of the building. In: APPLICATIONS OF THE PERFORMANCE CONCEPT IN BUILDING, Tel Aviv, 1996.

Proceedings... Tel Aviv, 1996. v. 2, p. 6-11. (adições do tipo pozolana). Os resíduos oriundos do beneficiamento de rochas ornamentais são exemplos de adição do tipo fíler, em cujo grupo está inserido o resíduo de serragem de pedra Cariri (RSPC), objeto de estudo deste trabalho.

Existem diversos estudos realizados por vários autores que utilizam fíler na produção de compostos à base de cimento Portland (GONÇALVES, 2000; GONÇALVES; MOURA; LEITE, 2003; LAMEIRAS, 2004; MOURA; GONÇALVES; LEITE, 2002; NEVES, 2002; CRUZ; LAMEIRAS, 2003; TENÓRIO, 2004; ALMEIDA et al., 2007; CORINALDESI; MORICONE; NAIK, 2010; ERGUN, 2011). Contudo, apenas Silva et al. (2008) utilizaram o resíduo de serragem de pedra Cariri em seu estudo com argamassas.

A pedra Cariri é explorada, há mais de 40 anos, para uso como revestimento no sul do estado do Ceará, nos municípios de Nova Olinda e Santana do Cariri, encravados na Chapada do Araripe (CASTRO, 2009). O RSPC é gerado em duas etapas do processo: na etapa de extração da lajota, com o uso da cortadeira móvel; e na etapa de esquadrejamento das placas de pedra Cariri, que se dá pela serragem das placas nas dimensões comerciais. Não existe, ainda, levantamento do volume gerado desses resíduos, devido à variação dos processos de exploração.

Nesse contexto, este trabalho apresenta os resultados do estudo de utilização do resíduo de serragem de pedra Cariri (RSRP) como adição mineral do tipo fíler, em substituição ao cimento, para produção de concretos. Procedeu-se à caracterização do resíduo e determinou-se sua influência nas propriedades mecânicas (resistência à compressão axial e à tração por compressão diametral) e nos parâmetros de durabilidade (absorção por imersão e por sucção capilar) dos concretos produzidos.

\section{Procedimento experimental}

A seguir são apresentadas as características dos materiais utilizados na confecção dos concretos estudados e os métodos utilizados na realização dos ensaios.

\section{Materiais}

\section{Resíduo de serragem de pedra Cariri}

A coleta do material foi realizada de acordo com a NBR 10007 (ABNT, 2004) - Amostragem de Resíduos. A amostra do RSPC foi coletada em 
uma empresa filiada à Cooperativa de Mineração dos Produtores da Pedra Cariri - Ceará (Coopedras), na cidade de Nova Olinda.

O volume de resíduo coletado foi em torno de 1 $\mathrm{m}^{3}$. Essa amostra pode ser considerada representativa e suficiente para o desenvolvimento da pesquisa. $\mathrm{O}$ resíduo foi coletado em forma de lama, portanto com altos teores de umidade. $\mathrm{Na}$ Figura 1 apresenta-se o processo de coleta do RSPC.

Para utilização do RSPC como adição mineral foi necessário um processo de beneficiamento do resíduo. Tal processo consistiu na secagem, destorroamento em britador de mandíbulas, para redução dos torrões a grãos de menor dimensão, e moagem do material destorroado. Nessa etapa foi utilizado o britador de mandíbulas da Princemaq, modelo C2015, para transformar aglomerados de RSPC que inicialmente tinham cerca de Dmáx = $200 \mathrm{~mm}$ para aglomerados com Dmáx $=6,3 \mathrm{~mm}$ $\mathrm{Na}$ Figura 2, ilustra-se o britador de mandíbulas utilizado na etapa do processamento do RSPC.

Em seguida foi realizada a moagem em moinho de bolas horizontal, CT 242, Servitech (comumente chamado "moinho periquito"), que conferiu ao RSPC o aspecto de pó, desejável para a utilização nos concretos. A carga utilizada foi de $700 \mathrm{~g}$ de bolas de alumina, para igual massa de RSPC. A moagem foi executada em diferentes tempos, para definição do mais adequado. O moinho utilizado é ilustrado na Figura 3.

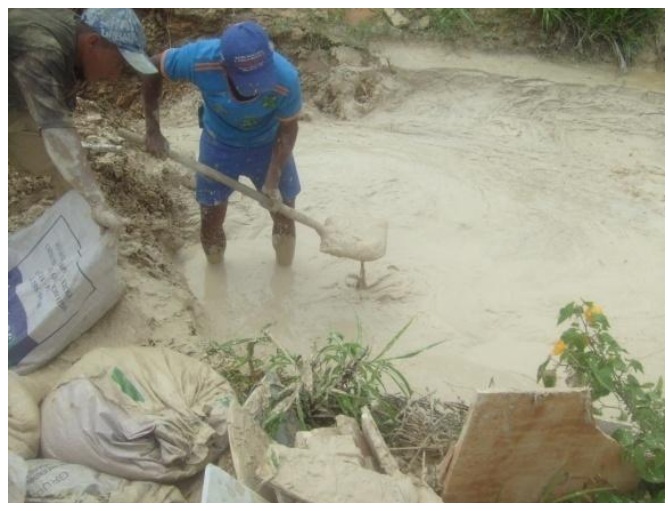

Figura 1 - Detalhamento da retirada do RSPC do tanque de decantação

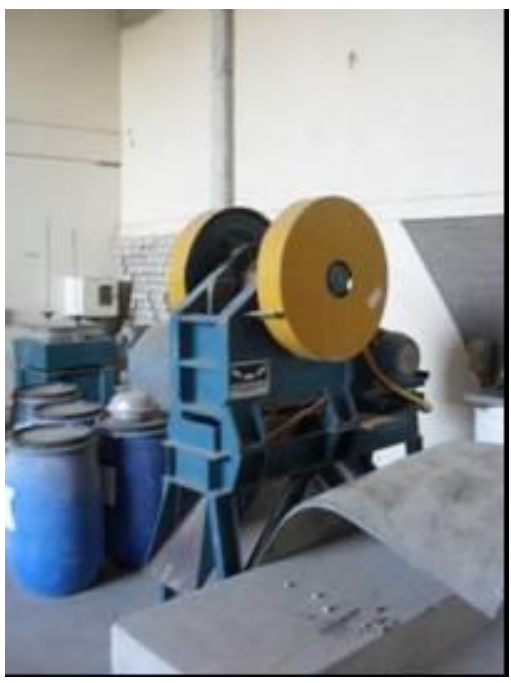

(a)

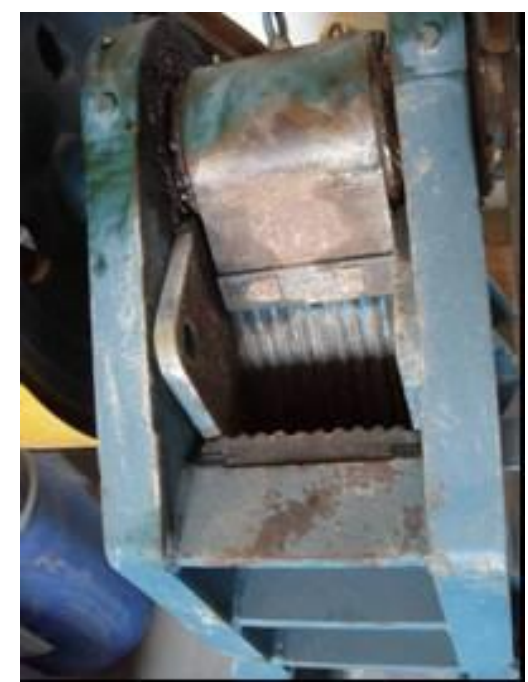

(b)

Figura 2 - (a) Britador de mandíbulas e (b) mandíbula do britador 


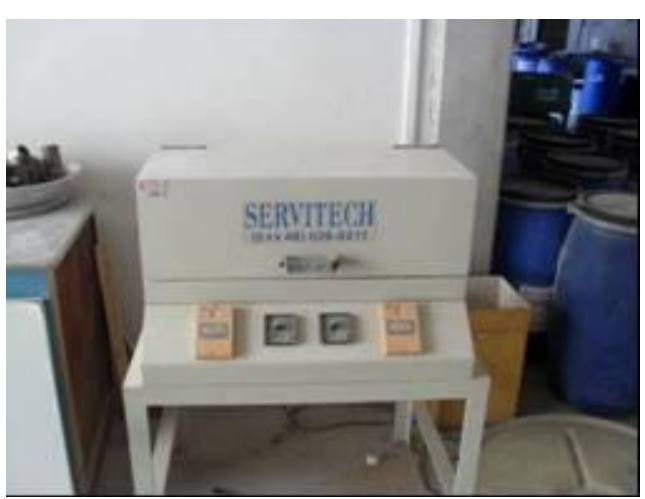

(a)

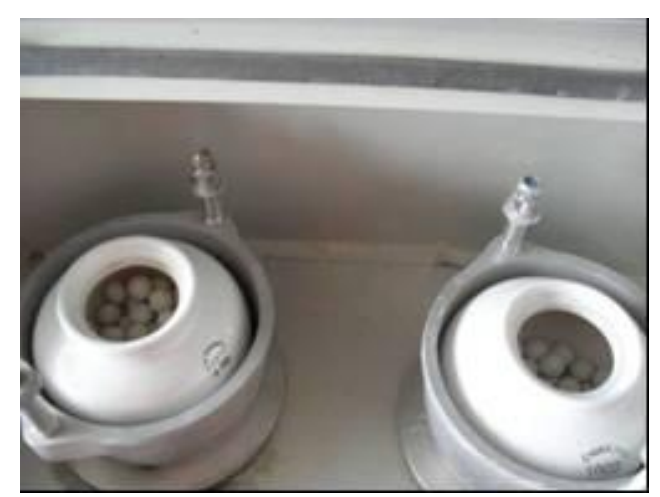

(b)

Figura 3 - (a) Aspecto do equipamento usado na moagem e (b) detalhe dos jarros e carga de corpos moedores de alumina

Foram determinadas a granulometria e a superfície específica do resíduo moído, em granulômetro a laser, MasterSizer 2000. Esse ensaio foi realizado no Laboratório de Estruturas (LABEST/COPPE/UFRJ), utilizando-se água destilada, com agitação de $1500 \mathrm{rpm}$. Na Tabela 1 estão apresentados dados da granulometria e superfície específica do RSPC para os diferentes tempos de moagem.

O melhor tempo de moagem foi definido a partir de um estudo quanto à resistência à compressão, aos 28 dias, em argamassas produzidas com $10 \%$ de substituição, em massa, do cimento pelo RSPC. O teor de $10 \%$ de RSPC foi escolhido com base no estudo desenvolvido por Moura, Gonçalves e Leite (2002). O traço da argamassa foi de 1:3,0:0,54 (cimento:areiafina:a/c), em massa. A relação $a / c$ foi mantida constante para todas as misturas. $\mathrm{Na}$ Tabela 2 estão apresentados os resultados de resistência à compressão das argamassas com RSPC para os diferentes tempos de moagem.

Com base nos resultados de resistência à compressão das argamassas, o melhor tempo de moagem para o RSPC foi de $2 \mathrm{~min}$, considerando que envolve menor consumo de energia para praticamente a mesma resistência. $\mathrm{O}$ diâmetro médio do RSPC para 2 min de moagem foi de 5,23 $\mu \mathrm{m}$.

A composição química do RSPC foi determinada no LABEST/COPPE/UFRJ, utilizando-se um EDX, modelo 720, da marca Shimadzu. Na Tabela
3 está apresentada a composição química obtida para o RSPC.

Pode-se observar que a pedra cariri é um material composto basicamente de óxido de cálcio, com mais de $95 \%$ desse constituinte em sua composição.

O RSPC possui uma massa específica de 2,67 $\mathrm{g} / \mathrm{cm}^{3}$.

Para identificar a presença de elementos cristalinos na composição do RSPC foi realizada uma análise de difração de raios $X(D R X)$, no Instituto de Química da UFBA, utilizando-se um difratômetro Shimadzu, modelo XRD6000, operando com radiação de $\mathrm{Cu}_{\mathrm{K} \alpha}(\lambda=1,5418 \AA)$ e monocromador de grafite, operando a uma tensão de $40 \mathrm{kV}$ e corrente de $30 \mathrm{~mA}$, na faixa de varredura de 5 a $80^{\circ}(2 \theta)$ e velocidade angular de $2 \%$ min. A Figura 4 apresenta o difratograma de raios $\mathrm{X}$ do resíduo, no qual se verifica a fase cristalina correspondente à calcita (comparada na Figura 4 com o padrão de calcita, em vermelho).

$O$ índice de atividade pozolânica do RSPC foi determinado de acordo com a NBR 5752 (ABNT, 1992). A Tabela 4 mostra os resultados do ensaio de pozolanicidade.

Observa-se que o índice de pozolanicidade foi de $56 \%$. Esse resultado, associado à estrutura predominantemente cristalina apresentada pelo RSPC (Figura 4), permite afirmar que o material não deve ser caracterizado como pozolânico.

Tabela 1 - Dados da granulometria do RSPC

\begin{tabular}{ccccc}
\hline $\begin{array}{c}\text { Tempos de } \\
\text { Moagem }\end{array}$ & $\begin{array}{c}\mathbf{D}_{\mathbf{1 0}} \\
(\boldsymbol{\mu m})\end{array}$ & $\begin{array}{c}\mathbf{D}_{\mathbf{5 0}} \\
(\boldsymbol{\mu \mathbf { m }})\end{array}$ & $\begin{array}{c}\mathbf{D}_{\mathbf{9 0}} \\
(\boldsymbol{\mu m})\end{array}$ & $\begin{array}{c}\text { Superfície } \\
\text { Específica } \\
\left(\mathbf{m}^{\mathbf{2}} / \mathbf{g}\right)\end{array}$ \\
\hline $2 \mathrm{~min}$ & 1,030 & 5,227 & 17,463 & 2,25 \\
$10 \mathrm{~min}$ & 0,991 & 4,689 & 15,851 & 2,39 \\
$30 \mathrm{~min}$ & 0,948 & 4,382 & 13,829 & 2,52 \\
\hline
\end{tabular}

10 Moura, W. A.; Leite, M. B.; Bastos, A. J. O. 
Tabela 2 - Resistência à compressão axial, aos 28 dias, e traço utilizado para produção das argamassas estudadas

\begin{tabular}{cccc}
\hline Tempo de moagem (min) & $\begin{array}{c}\text { Resistência } \\
(\mathbf{M P a})\end{array}$ & $\begin{array}{c}\text { C.V. } \\
(\boldsymbol{\%})\end{array}$ & $\begin{array}{c}\text { Traço } \\
(\mathbf{c}: \mathbf{a}: \mathbf{a} / \mathbf{c})\end{array}$ \\
\hline 2 & 27,4 & 9,78 & \multirow{2}{*}{$1: 3: 0,54$} \\
\cline { 1 - 3 } & 27,9 & 9,74 & \\
\hline 10 & 27,7 & 4,94 & \\
\hline
\end{tabular}

Tabela 3 - Composição química do RSPC

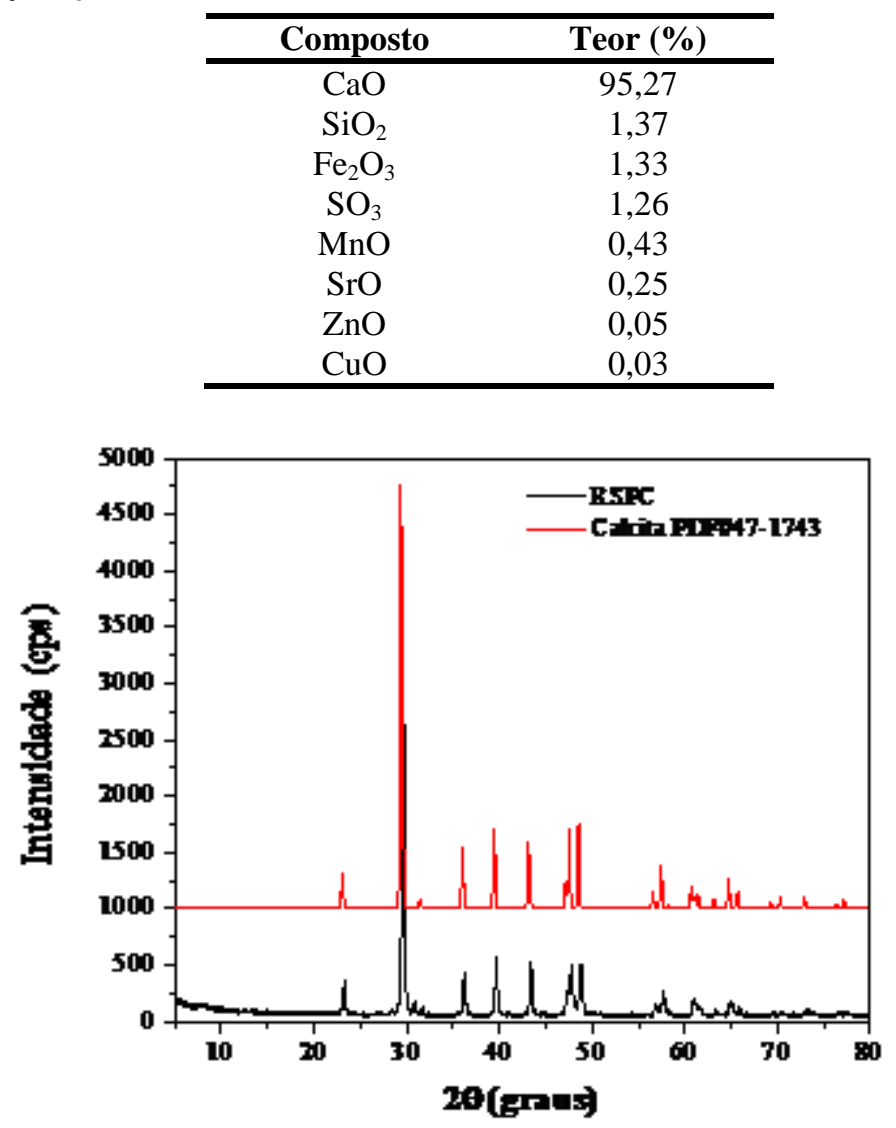

Figura 4 - Difratograma de uma amostra de RSPC

Tabela 4 - Composição química do RSPC

\begin{tabular}{cccc}
\hline Argamassa & $\begin{array}{c}\text { Água } \\
\text { Requerida } \\
(\boldsymbol{\%})\end{array}$ & $\begin{array}{c}\text { Resistência à } \\
\text { Compressão } \\
(\mathbf{M P a})\end{array}$ & $\begin{array}{c}\text { Índice de } \\
\text { Atividade (\%) }\end{array}$ \\
\hline $65 \%$ CPI S + 35\% RSPC & 99 & 13,5 & 56 \\
CP I - S & 98 & 24 & 100 \\
Especificações & $<110$ & - & $\geq 75$ \\
\hline
\end{tabular}




\section{Cimento}

O cimento utilizado neste trabalho foi o CP II Z 32 - RS, cimento Portland composto com pozolana, por ser um dos cimentos comumente utilizados na região onde é gerado o resíduo. Na Tabela 5 encontram-se a composição química, os ensaios físicos e a resistência à compressão do cimento.

\section{Agregado miúdo}

A areia utilizada no estudo foi uma areia grossa, de origem quartzosa, coletada no Rio Jacuípe, localizado no município de Feira de Santana, BA. Os ensaios de caracterização do agregado miúdo encontram-se na Tabela 6.

\section{Agregado Graúdo}

Foi utilizado como agregado graúdo brita de origem granítica, e os resultados dos ensaios para sua caracterização encontram-se na Tabela 7 .

\section{Produção e avaliação dos concretos}

Para dosagem dos concretos utilizou-se a metodologia de dosagem do IPT/EPUSP (HELENE; TERZIAN, 1992). Como fator de controle adotou-se a trabalhabilidade de $(100 \pm 20)$ $\mathrm{mm}$, medida através do ensaio de abatimento de tronco de cone, NBR NM 67 (ABNT, 1998). Os traços foram determinados levando-se em consideração três relações a/c $(0,45,0,55$ e 0,65$)$. $\mathrm{Na}$ relação a/c, o termo do denominador engloba o somatório do cimento e o RSPC. O teor de argamassa seca estabelecido foi de 52\% para todos os concretos produzidos. Os traços unitários, em massa, estão apresentados na Tabela 8.

Tabela 5 - Composição química, resistência e índices físicos do cimento

\begin{tabular}{cccc}
\hline Compostos & Teor $(\%)$ & \multicolumn{2}{c}{ Resistência à Compressão (MPa) } \\
\hline $\mathrm{CaO}$ & 61,34 & Idade (dias) & 26,5 \\
$\mathrm{SiO}_{2}$ & 21,49 & 3 & 29,1 \\
$\mathrm{Al}_{2} \mathrm{O}_{3}$ & 5,81 & 7 & 34,9 \\
$\mathrm{SO}_{3}$ & 5,21 & 28 & 180 \\
$\mathrm{Fe}_{2} \mathrm{O}_{3}$ & 3,73 & Ensaios Físicos \\
$\mathrm{K}_{2} \mathrm{O}$ & 1,80 & Início de pega $($ min.) & 305 \\
$\mathrm{TiO}_{2}$ & 0,33 & Fim de pega (min.) & 0 \\
$\mathrm{SrO}$ & 0,24 & Expansão a quente $(\mathrm{mm})$ & 0,5 \\
$\mathrm{MnO}$ & 0,04 & Finura na peneira $75 \mu \mathrm{m}(\%)$ & 2,90 \\
$\mathrm{Rb}_{2} \mathrm{O}$ & 0,01 & Massa específica $\left(\mathrm{g} / \mathrm{m}^{3}\right)$ & 17 \\
$\mathrm{Y}_{2} \mathrm{O}_{3}$ & 0,01 & Diâmetro médio $(\mu \mathrm{m})$ & \\
\hline
\end{tabular}

Tabela 6 - Distribuição granulométrica e índices físicos da areia

\begin{tabular}{cc}
\hline Abertura de Peneira $(\mathbf{m m})$ & \% Retida Acumulada \\
\hline 4,8 & 0 \\
2,4 & 3 \\
1,2 & 12 \\
0,6 & 39 \\
0,3 & 81 \\
0,15 & 98 \\
$\langle 0,15$ & 100 \\
\hline Dimensão máxima característica $(\mathrm{mm})$ & 2,4 \\
\hline Módulo de finura & 2,32 \\
\hline Massa específica $\left(\mathrm{g} / \mathrm{cm}^{3}\right)$ & 2,54 \\
\hline Absorção $(\%)$ & 0,76 \\
\hline
\end{tabular}

12 Moura, W. A.; Leite, M. B.; Bastos, A. J. O. 
Tabela 7 - Distribuição granulométrica e índices físicos da brita

\begin{tabular}{cc}
\hline Abertura de Peneira $(\mathbf{m m})$ & \% Retida Acumulada \\
\hline 25 & 0 \\
19 & 17 \\
12,5 & 96 \\
9,5 & 100 \\
6,3 & 100 \\
4,8 & 100 \\
$\iota 4,8$ & 100,00 \\
\hline Dimensão máxima característica $(\mathrm{mm})$ & 25,0 \\
\hline Módulo de finura & 7,17 \\
\hline Massa específica $\left(\mathrm{g} / \mathrm{cm}^{3}\right)$ & 2,78 \\
\hline Absorção $(\%)$ & 0,35 \\
\hline
\end{tabular}

Tabela 8 - Traços unitários, em massa, consumos de cimento e valores de abatimento dos concretos estudados

\begin{tabular}{ccccccc}
\hline $\begin{array}{c}\text { Teor de } \\
\begin{array}{c}\text { Substituição } \\
(\boldsymbol{\%})\end{array}\end{array}$ & $\begin{array}{c}\text { Relação } \\
\mathbf{a} / \mathbf{c}\end{array}$ & Cimento & $\begin{array}{c}\text { Ag. } \\
\text { Miúdo }\end{array}$ & $\begin{array}{c}\text { Ag. } \\
\text { Graúdo }\end{array}$ & $\begin{array}{c}\text { Consumo de } \\
\text { Cimento (kg/m } \mathbf{n})\end{array}$ & $\begin{array}{c}\text { Abatimento } \\
(\mathbf{m m})\end{array}$ \\
\hline \multirow{2}{*}{0} & 0,45 & 1 & 2,57 & 3,30 & 470,8 & 115 \\
& 0,55 & 1 & 1,95 & 2,73 & 394,1 & 120 \\
\hline \multirow{2}{*}{10} & 0,65 & 1 & 1,34 & 2,16 & 334,8 & 85 \\
\hline & 0,45 & 0,9 & 2,57 & 3,30 & 423,7 & 100 \\
& 0,55 & 0,9 & 1,95 & 2,73 & 354,7 & 115 \\
& 0,65 & 0,9 & 1,34 & 2,16 & 301,4 & 120 \\
\hline & 0,45 & 0,8 & 2,57 & 3,30 & 376,6 & 95 \\
& 0,55 & 0,8 & 1,95 & 2,73 & 315,3 & 100 \\
\hline
\end{tabular}

Para a avaliação dos concretos foram moldados quatro corpos de prova (CPs), por idade, de $(\phi 100 \times \mathrm{x} 200) \mathrm{mm}$ para determinação da resistência à compressão, de acordo com a NBR 5739 (ABNT, 2007). Foram moldados, ainda, 2 CPs ( $\$ 100 x H 200)$ mm para determinação da resistência à tração por compressão diametral, de acordo com a NBR 7222 (ABNT, 1994), e 2 CPs ( $\phi 100 x H 200)$ mm para determinação da absorção por imersão e do índice de vazios, de acordo com a NBR 9778 (ABNT, 2005).

Os concretos também foram avaliados quanto à absorção por sucção capilar. Esse ensaio avalia a absorção por possíveis capilares no concreto. Como não existe no Brasil normalização para o ensaio de absorção por sucção capilar, foi adotado o método de Kelham (1988), adaptado por Gopalan (1996). O princípio do ensaio, conforme descrito por Moura (2000), consiste em avaliar o ganho de massa de CPs, medido em intervalos de tempo preestabelecidos. Com os valores medidos, plotam-se os pontos de acúmulo de massa dos CPs submersos, em função da raiz quadrada do tempo. Posteriormente, são interpoladas duas retas em função dos pontos plotados: a primeira referente ao período de absorção inicial; e a segunda no trecho de saturação dos CPs. Este último caracteriza-se por uma diminuição significativa do ganho de massa das amostras. Denomina-se nick point o ponto de interseção entre as duas retas, que corresponde ao início da saturação do corpo de prova. Dessa forma, calcula-se taxa de absorção, resistência capilar e porosidade efetiva. Com a inclinação da reta de absorção inicial e a área da seção transversal do corpo de prova, encontra-se a taxa de absorção, em $\mathrm{g} / \mathrm{h}^{1 / 2}$. A resistência capilar, expressa em $\mathrm{h} / \mathrm{m}^{2}$, é obtida através da relação entre o nick point (ponto de interseção entre as duas retas ou ponto de saturação) e o quadrado da espessura do corpo de prova. A forma de cálculo da resistência capilar está apresentada na Equação 1 (GJORV, 1994):

$\mathrm{M}=\mathrm{t} \mathrm{s} / \mathrm{e}^{2}$

Eq. 1

Onde:

$\mathrm{M}$ - Resistência capilar $\left(\mathrm{h} / \mathrm{m}^{2}\right)$;

ts - Abcissa do ponto de saturação $\left(h^{1 / 2}\right)$; e

e - espessura do corpo de prova (m). 
Para este ensaio foram utilizados dois CPs para cada traço de concreto estudado.

O adensamento dos CPs foi realizado com um vibrador de agulha de imersão. Eles foram curados ao ar nas primeiras $24 \mathrm{~h}$ e, após a desmoldagem, levados para câmara úmida e mantidos imersos em água com cal até a idade de ensaio.

\section{Apresentação e análise dos resultados}

A seguir são apresentados os resultados dos ensaios realizados no concreto no estado endurecido. Na Tabela 9 são apresentados os resultados dos ensaios de resistência mecânica (compressão axial e tração por compressão diametral) e os resultados dos ensaios das propriedades relacionadas com a durabilidade (absorção por imersão, índice de vazios e absorção por sucção capilar).

Tabela 9 - Resultados de resistência à compressão axial dos concretos produzidos

\begin{tabular}{|c|c|c|c|c|c|c|c|}
\hline \multirow[b]{3}{*}{ MISTURA } & \multirow[b]{3}{*}{$\mathbf{a} / \mathbf{c}$} & \multicolumn{6}{|c|}{ Idade } \\
\hline & & \multicolumn{3}{|c|}{7 dias } & \multicolumn{3}{|c|}{28 dias } \\
\hline & & fc (MPa) & $\begin{array}{c}\text { fcm } \\
(\mathrm{MPa})\end{array}$ & $\begin{array}{l}\text { C.V. } \\
(\%)\end{array}$ & fc (MPa) & $\begin{array}{c}\text { fcm } \\
(\mathrm{MPa})\end{array}$ & $\begin{array}{l}\text { C.V. } \\
(\%)\end{array}$ \\
\hline \multirow{12}{*}{ REF } & \multirow{4}{*}{0,45} & 28,4 & \multirow{4}{*}{27,0} & \multirow{4}{*}{9,1} & 33,0 & \multirow{4}{*}{34,3} & \multirow{4}{*}{3,4} \\
\hline & & 23,5 & & & 35,8 & & \\
\hline & & 27,0 & & & 34,3 & & \\
\hline & & 28,9 & & & 34,3 & & \\
\hline & \multirow{4}{*}{0,55} & 21,8 & \multirow{4}{*}{21,5} & \multirow{4}{*}{2,0} & 28,4 & \multirow{4}{*}{27,7} & \multirow{4}{*}{3,4} \\
\hline & & 21,9 & & & 28,4 & & \\
\hline & & 21,3 & & & 26,4 & & \\
\hline & & 21,0 & & & 27,7 & & \\
\hline & \multirow{4}{*}{0,65} & 19,7 & \multirow{4}{*}{18,2} & \multirow{4}{*}{6,8} & 20,7 & \multirow{4}{*}{21,0} & \multirow{4}{*}{6,3} \\
\hline & & 17,0 & & & 22,0 & & \\
\hline & & 17,4 & & & 22,1 & & \\
\hline & & 18,6 & & & 19,3 & & \\
\hline \multirow{12}{*}{$10 \% \mathrm{RSPC}$} & \multirow{4}{*}{0,45} & 22,6 & \multirow{4}{*}{24,5} & \multirow{4}{*}{5,5} & 32,0 & \multirow{4}{*}{31,3} & \\
\hline & & 24,8 & & & 31,4 & & \\
\hline & & 25,6 & & & 28,6 & & 6,3 \\
\hline & & 25,0 & & & 33,3 & & \\
\hline & & 21,4 & & & 25,6 & & \\
\hline & & 19,8 & & & 24,4 & & \\
\hline & 0,55 & 19,6 & 20,4 & 4,1 & 22,8 & 23,9 & 5,8 \\
\hline & & 20,7 & & & 22,7 & & \\
\hline & & 16,4 & & & 21,8 & & \\
\hline & & 16,5 & & & 22,3 & & \\
\hline & 0,65 & 18,2 & 17,2 & 5,2 & 21,6 & 22,3 & 3,4 \\
\hline & & 17,5 & & & 23,3 & & \\
\hline & & 23,0 & & & 31,3 & & \\
\hline & 045 & 25,6 & & & 28,3 & & 72 \\
\hline & 0,45 & 23,8 & 23,4 & 8,1 & 26,7 & 28,4 & 7,2 \\
\hline & & 21,1 & & & 27,5 & & \\
\hline & & 20,9 & & & 23,1 & & \\
\hline & & 19,2 & & & 22,1 & & \\
\hline $20 \%$ RSPC & 0,55 & 19,0 & 19,4 & 5,2 & 22,8 & 22,7 & 1,9 \\
\hline & & 18,6 & & & 22,8 & & \\
\hline & & 14,4 & & & 16,3 & & \\
\hline & & 16,4 & & & 14,7 & & \\
\hline & 0,65 & 15,9 & 14,9 & 11,4 & 16,5 & 16,2 & 7,1 \\
\hline & & 12,7 & & & 17,5 & & \\
\hline
\end{tabular}

Nota: Legenda:

a/c - relação água/ (cimento+RSPC);

$\mathrm{fc}=$ resistência à compressão;

$\mathrm{fcm}=$ resistência à compressão média; e

C.V. - coeficiente de variação. 
A influência do teor de substituição do RSPC nas propriedades dos concretos endurecidos e a interação entre as variáveis relacionadas foram avaliadas estatisticamente por análise de variância (ANOVA), com a utilização do software Statistica. O nível de significância adotado para as análises foi de $5 \%$.

\section{Resistência à compressão axial}

Os ensaios de resistência à compressão axial foram realizados de acordo com a norma NBR 5739 (ABNT, 2007). Foram ensaiados quatro CPs para cada mistura e idade ( 7 e 28 dias). Na Tabela 9 estão apresentados os resultados de resistência à compressão dos concretos produzidos.

Observa-se que o coeficiente de variação, de um modo geral, foi bem maior para as misturas com
RSPC, exceto para os concretos 10\%RSPC $(\mathrm{a} / \mathrm{c}=0,65)$ e $20 \% \mathrm{RSPC} \quad(\mathrm{a} / \mathrm{c}=0,55)$. Maiores coeficientes de variação indicam maiores dispersões nos resultados, ou seja, maiores desvios relativamente à média dos resultados de cada grupo. Em outras palavras, o uso do RSPC promove maior heterogeneidade dos resultados. Vale salientar que é comum encontrar valores de coeficiente de variação para resistência à compressão na faixa dos valores apresentados neste estudo.

A Figura 5 apresenta o comportamento dos concretos quanto à resistência à compressão axial aos 7 e 28 dias.

Na Tabela 10 são apresentados os resultados da ANOVA.

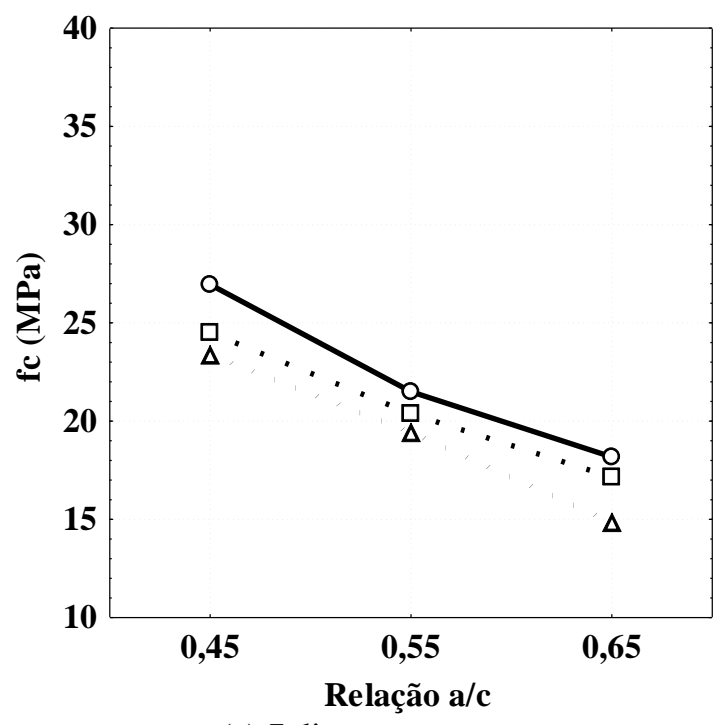

(a) 7 dias

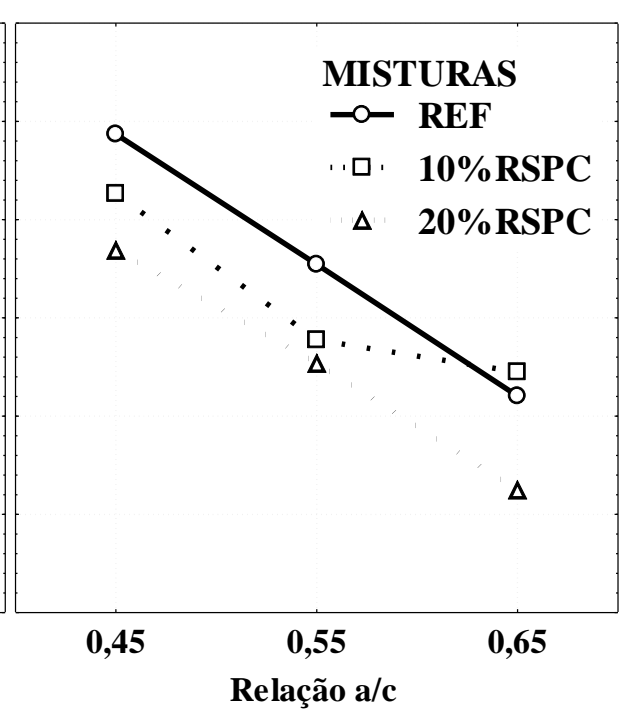

(b) 28 dias

Figura 5 - Curvas de comportamento dos concretos quanto à resistência à compressão axial

Tabela 10 - Resultados da ANOVA de resistência à compressão axial dos concretos produzidos

\begin{tabular}{cccccc}
\hline Fator & GDL & MQ & Fcalculado & F0,05 & Significância \\
\hline A - Teor & 2 & 102,44 & 54,28 & 3,17 & $\mathrm{~S}$ \\
B - a/c & 2 & 588,18 & 311,60 & 3,17 & $\mathrm{~S}$ \\
C - Idade & 1 & 385,49 & 204,23 & 4,02 & $\mathrm{~S}$ \\
AB & 4 & 7,11 & 3,76 & 2,55 & $\mathrm{~S}$ \\
AC & 2 & 8,73 & 4,62 & 3,17 & $\mathrm{~S}$ \\
BC & 2 & 16,89 & 8,95 & 3,17 & $\mathrm{~S}$ \\
ABC & 4 & 3,28 & 1,74 & 2,55 & $\mathrm{NS}$ \\
Erro & 54 & 1,886 & - & - & - \\
\hline
\end{tabular}

Nota: Legenda:

$\mathrm{GDL}=$ Graus de liberdade;

Fcalculado = Valor calculado de F;

$M Q=$ Média quadrada;

F0,05 = Valor tabelado de f para o nível de significância de 5\%; e

$\mathrm{S}=$ Significativo;

NS = Não significativo. 
Na Tabela 10 pode-se verificar que as variáveis teor de substituição, relação a/c e idade, analisadas isoladamente, apresentam influência significativa sobre a resistência à compressão axial. Também foi verificado que existe influência significativa nas interações das variáveis teor de substituição e relação a/c; teor de substituição e idade; e relação a/c e idade. No entanto, não há interação entre as variáveis teor de substituição, relação a/c e idade. Portanto, pode-se dizer que o teor de adição, a relação a/c e a idade provocam alterações significativas na resistência à compressão axial dos concretos.

Com base nos resultados de 28 dias pode-se observar que os concretos com RSPC apresentaram menor resistência para todos os teores de resíduo e todas as relações a/c. Quanto maior o teor de substituição de cimento por RSPC, menor a resistência à compressão axial. A redução da resistência chega a ser de $23 \%$ na mistura com teor de substituição de $20 \%$ e relação a/c=0,65. Foi observado também que para maiores teores de relação a/c é maior a influência do teor de substituição de cimento por RSPC na resistência à compressão axial. Apesar de o tamanho médio dos grãos do RSPC ser menor do que o do cimento, seu efeito fíler não foi preponderante sobre o efeito cimentante proporcionado pelo cimento.

\section{Resistência à tração por compressão diametral}

A Tabela 11 apresenta os resultados dos ensaios de resistência à tração por compressão diametral.

Pode-se observar que para algumas misturas o coeficiente de variação foi maior que $10 \%$. A dispersão foi maior para algumas misturas quando a idade do concreto foi de 7 dias, portanto, período mais vulnerável. Entretanto, tomando-se como base os resultados de 28 dias, o coeficiente de variação está na faixa comumente encontrada para resistência à tração por compressão diametral.

A Figura 6 apresenta as curvas de comportamento dos concretos quanto à resistência à tração por compressão diametral aos 7 e 28 dias.

Tabela 11 - Resultados de resistência à tração por compressão diametral dos concretos produzidos

\begin{tabular}{|c|c|c|c|c|c|c|c|}
\hline \multirow[b]{3}{*}{ MISTURA } & \multirow[b]{3}{*}{$\mathrm{a} / \mathrm{c}$} & \multicolumn{6}{|c|}{ Idade } \\
\hline & & \multicolumn{3}{|c|}{7 dias } & \multicolumn{3}{|c|}{28 dias } \\
\hline & & $\begin{array}{c}\mathrm{ft} ' \mathrm{~d} \\
(\mathrm{MPa})\end{array}$ & $\begin{array}{l}\mathrm{ft}^{\prime} \mathrm{dm} \\
(\mathrm{MPa})\end{array}$ & $\mathrm{CV}$ & $\begin{array}{c}\mathrm{ft}^{\prime} \mathrm{d} \\
(\mathrm{MPa})\end{array}$ & $\begin{array}{l}\mathrm{ft} \text { 'dm } \\
(\mathrm{MPa})\end{array}$ & $\mathrm{CV}$ \\
\hline \multirow{3}{*}{ REF } & 0,45 & $\begin{array}{l}2,5 \\
2,4\end{array}$ & 2,5 & 2,8 & $\begin{array}{l}3,1 \\
3,1\end{array}$ & 3,1 & 0,0 \\
\hline & 0,55 & $\begin{array}{l}1,8 \\
1,9 \\
\end{array}$ & 1,9 & 3,7 & $\begin{array}{l}2,1 \\
2,2 \\
\end{array}$ & 2,2 & 3,2 \\
\hline & 0,65 & $\begin{array}{l}2,0 \\
1,4 \\
\end{array}$ & 1,7 & 25,0 & $\begin{array}{l}1,9 \\
2,2 \\
\end{array}$ & 2,1 & 10,1 \\
\hline \multirow{3}{*}{$10 \%$ RSPC } & 0,45 & $\begin{array}{l}2,5 \\
2,4 \\
\end{array}$ & 2,5 & 2,8 & $\begin{array}{l}2,7 \\
2,7 \\
\end{array}$ & 2,7 & 0,0 \\
\hline & 0,55 & $\begin{array}{l}1,8 \\
1,9\end{array}$ & 1,9 & 3,7 & $\begin{array}{l}2,2 \\
2,2 \\
\end{array}$ & 2,2 & 0,0 \\
\hline & 0,65 & $\begin{array}{l}1,4 \\
1,7 \\
\end{array}$ & 1,6 & 13,3 & $\begin{array}{l}1,8 \\
2,1 \\
\end{array}$ & 2,0 & 10,6 \\
\hline \multirow{3}{*}{$20 \%$ RSPC } & 0,45 & $\begin{array}{l}2,3 \\
2,3 \\
\end{array}$ & 2,3 & 0,0 & $\begin{array}{l}2,4 \\
2,7 \\
\end{array}$ & 2,6 & 8,2 \\
\hline & 0,55 & $\begin{array}{l}1,7 \\
1,7 \\
\end{array}$ & 1,7 & 0,0 & $\begin{array}{l}2,2 \\
2,2 \\
\end{array}$ & 2,2 & 0,0 \\
\hline & 0,65 & $\begin{array}{l}1,4 \\
1,5\end{array}$ & 1,5 & 4,7 & $\begin{array}{l}1,9 \\
2,1\end{array}$ & 2,0 & 7,1 \\
\hline
\end{tabular}

Nota: Legenda:

$\mathrm{ft}^{\prime} \mathrm{d}=$ resistência à tração por compressão diametral; e

$\mathrm{ft}^{\prime} \mathrm{dm}$ = resistência à tração por compressão diametral média. 
Pode-se observar que para algumas misturas o coeficiente de variação foi maior que $10 \%$. A dispersão foi maior para algumas misturas quando a idade do concreto foi de 7 dias, portanto, período mais vulnerável. Entretanto, tomando-se como base os resultados de 28 dias, o coeficiente de variação está na faixa comumente encontrada para resistência à tração por compressão diametral.

A Figura 6 apresenta as curvas de comportamento dos concretos quanto à resistência à tração por compressão diametral aos 7 e 28 dias.
Na Tabela 12 são apresentados os resultados da ANOVA.

Os resultados da Tabela 12 mostram que existe influência significativa dos fatores isolados - teor de substituição, relação a/c e idade - na resistência à tração por compressão diametral dos concretos. Verificou-se, ainda, que não houve influência significativa das interações entre teor de substituição e relação a/c, teor de substituição e idade, relação a/c e idade e teor de substituição, relação a/c e idade na propriedade estudada.

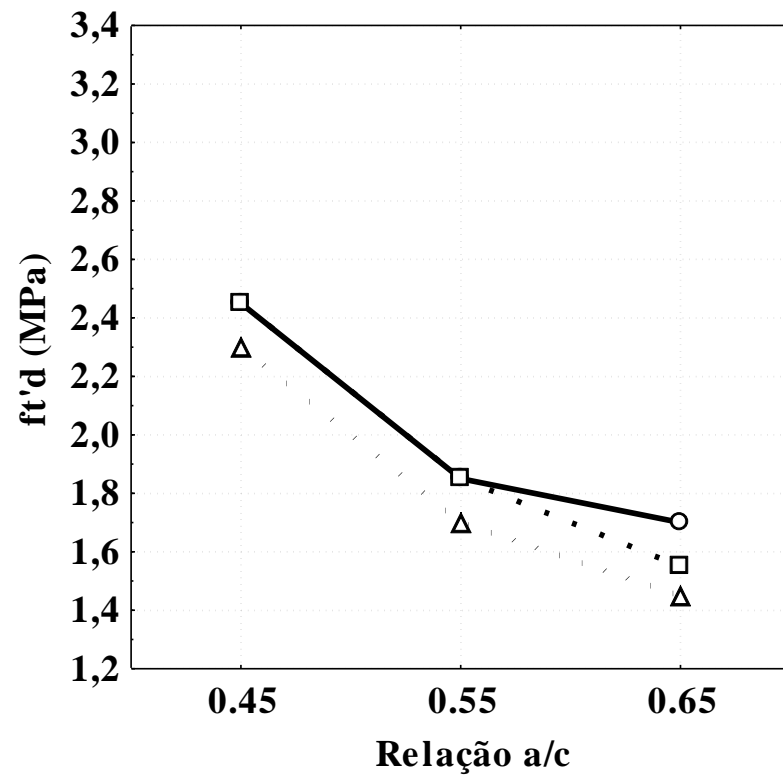

(a) 7 dias

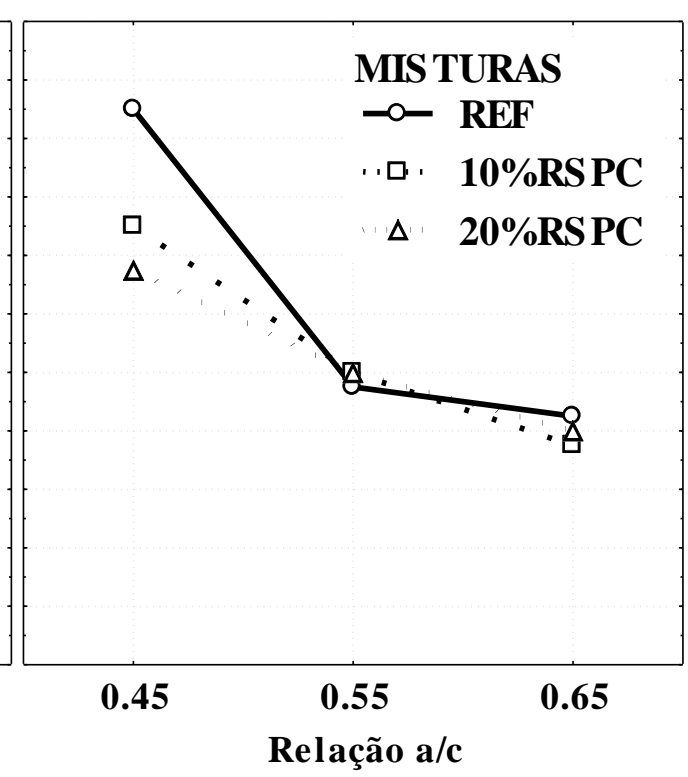

(b) 28 dias

Figura 6 - Curvas de comportamento quanto à resistência à tração por compressão diametral dos concretos produzidos

Tabela 12 - Resultados da ANOVA de resistência à tração por compressão diametral dos concretos produzidos

\begin{tabular}{cccccc}
\hline Fator & GDL & MQ & Fcalculado & F0,05 & Significância \\
\hline A - Teor & 2 & 0,101 & 4,439 & 3,55 & S \\
B - a/c & 2 & 2,114 & 92,793 & 3,55 & S \\
C - Idade & 1 & 1,440 & 63,219 & 4,41 & S \\
AB & 4 & 0,269 & 1,183 & 2,93 & NS \\
AC & 2 & 0,010 & 0,439 & 3,55 & NS \\
BC & 2 & 0,003 & 0,110 & 3,55 & NS \\
ABC & 4 & 0,033 & 1,427 & 2,93 & NS \\
Erro & 18 & 0,023 & - & - & - \\
\hline
\end{tabular}

Nota: Legenda:

GDL = Graus de liberdade;

Fcalculado = Valor calculado de F;

$M Q=$ Média quadrada;

F0,05 = Valor tabelado de f para o nível de significância de 5\%;

$\mathrm{S}=$ Significativo; $\mathrm{e}$

NS = Não significativo. 
Analisando os resultados de resistência média de 28 dias, pode-se observar que para os concretos com relação a/c=0,45 a utilização de RSPC, para todos os teores de substituição utilizados, proporcionou redução na resistência à tração por compressão diametral. Por outro lado, a resistência à tração por compressão diametral foi igual para todos os concretos com relação $a / c=0,55$, e praticamente igual para os concretos com relação $\mathrm{a} / \mathrm{c}=0,65$. Esse comportamento pode ser explicado pelo fato de que em concretos mais porosos (maior relação a/c) o efeito fíler é mais pronunciado.

\section{Absorção por imersão}

Na Tabela 13 estão apresentados os resultados de absorção e índice de vazios dos concretos produzidos.

Pode-se verificar que tanto para absorção quanto para o índice de vazios foi pequena a variabilidade dos resultados para cada mistura, o que permite a obtenção de uma análise mais segura da influência do RSPC sobre as propriedades avaliadas.

A Figura 7 mostra o comportamento quanto à absorção das misturas estudadas.
Na Tabela 14 são apresentados os resultados da ANOVA.

Os resultados da Tabela 14 mostram que existe influência significativa do fator isolado relação $\mathrm{a} / \mathrm{c}$ sobre a absorção por imersão dos concretos. Verificou-se, ainda, que houve influência significativa da interação entre teor de substituição e relação $\mathrm{a} / \mathrm{c}$.

Na Tabela 15 são apresentados os resultados da ANOVA para o índice de vazios.

Os resultados da Tabela 15 mostram que existe influência significativa do fator isolado relação $\mathrm{a} / \mathrm{c}$ sobre o índice de vazios dos concretos. Verificouse, ainda, que houve influência significativa da interação entre teor de substituição e relação a/c.

O comportamento dos concretos quanto ao índice de vazios foi semelhante ao da absorção por imersão. Nessas propriedades o efeito de preenchimento do RSPC teve maior influência sobre os resultados obtidos do que na resistência à compressão. Nesta última, o efeito cimentante é preponderante em relação ao efeito fíler.

Tabela 13 - Resultados de absorção e índice de vazios

\begin{tabular}{|c|c|c|c|c|c|c|c|}
\hline MISTURA & $\mathbf{a} / \mathbf{c}$ & $\begin{array}{c}\text { Abs. } \\
(\%)\end{array}$ & $\begin{array}{c}\text { Abs. Média } \\
(\%)\end{array}$ & $\begin{array}{l}\text { C.V. } \\
(\%)\end{array}$ & $\begin{array}{l}\text { I.V. } \\
(\%)\end{array}$ & $\begin{array}{c}\text { I.V. } \\
\text { Médio } \\
(\%)\end{array}$ & $\begin{array}{l}\text { C.V. } \\
(\%)\end{array}$ \\
\hline \multirow{3}{*}{ REF } & 0,45 & $\begin{array}{l}6,6 \\
6,5\end{array}$ & 6,6 & 1,1 & $\begin{array}{l}15,1 \\
14,8\end{array}$ & 15,0 & 1,4 \\
\hline & 0,55 & $\begin{array}{l}6,9 \\
6,9\end{array}$ & 6,9 & 0,0 & $\begin{array}{l}15,5 \\
15,6\end{array}$ & 15,5 & 0,5 \\
\hline & 0,65 & $\begin{array}{l}6,7 \\
6,7 \\
\end{array}$ & 6,7 & 0,0 & $\begin{array}{l}15,2 \\
15,1 \\
\end{array}$ & 15,2 & 0,5 \\
\hline \multirow{3}{*}{$10 \%$ RSPC } & 0,45 & $\begin{array}{l}6,3 \\
6,6 \\
\end{array}$ & 6,4 & 3,3 & $\begin{array}{l}14,4 \\
14,9 \\
\end{array}$ & 14,6 & 2,3 \\
\hline & 0,55 & $\begin{array}{l}6,3 \\
6,4\end{array}$ & 6,3 & 1,1 & $\begin{array}{l}14,4 \\
14,7\end{array}$ & 14,6 & 1,4 \\
\hline & 0,65 & $\begin{array}{l}7,1 \\
7,1\end{array}$ & 7,1 & 0,0 & $\begin{array}{l}16,1 \\
16,1\end{array}$ & 16,1 & 0,0 \\
\hline \multirow{3}{*}{$20 \%$ RSPC } & 0,45 & $\begin{array}{l}6,5 \\
6,5\end{array}$ & 6,5 & 0,0 & $\begin{array}{l}14,7 \\
14,7\end{array}$ & 14,7 & 0,0 \\
\hline & 0,55 & $\begin{array}{l}6,9 \\
6,8\end{array}$ & 6,8 & 1,0 & $\begin{array}{l}15,4 \\
15,2\end{array}$ & 15,3 & 1,0 \\
\hline & 0,65 & $\begin{array}{l}6,8 \\
6,6\end{array}$ & 6,7 & 2,1 & $\begin{array}{l}15,3 \\
14,9\end{array}$ & 15,1 & 1,8 \\
\hline
\end{tabular}

Nota: Legenda:

$a / c=$ relação água $/($ cimento+rspc);

Abs = absorção; e

I.V. = índice de vazios.

18 Moura, W. A.; Leite, M. B.; Bastos, A. J. O. 


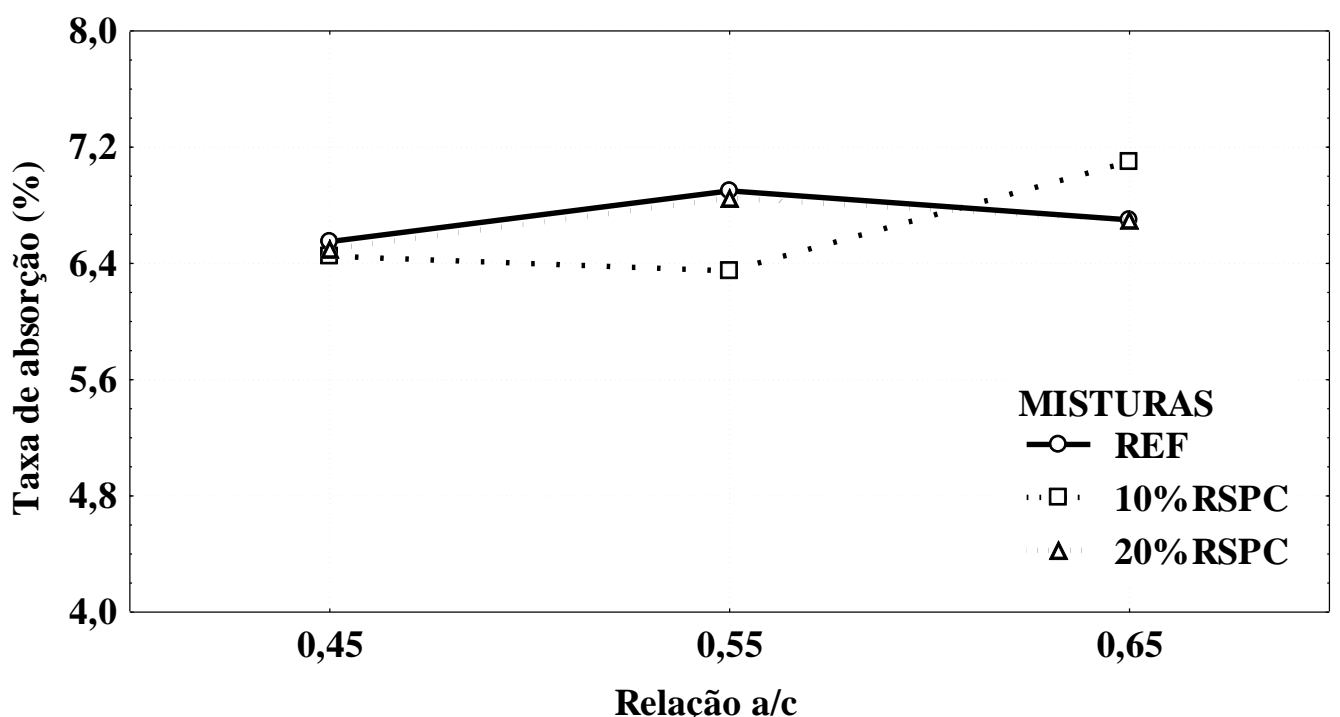

Figura 7 - Comportamento dos concretos quanto à absorção por imersão

Tabela 14 - Resultados da ANOVA de absorção por imersão dos concretos produzidos

\begin{tabular}{cccccc}
\hline Fator & GDL & MQ & Fcalculado & F0,05 & Significância \\
\hline A - Teor & 2 & 0,010556 & 1,18750 & 4,26 & NS \\
B - a/c & 2 & 0,168889 & 19,00000 & 4,26 & S \\
AB & 4 & 0,143056 & 16,09375 & 3,63 & $\mathrm{~S}$ \\
Erro & 9 & 0,008889 & - & - & - \\
\hline
\end{tabular}

Nota: Legenda:

$\mathrm{GDL}=$ Graus de liberdade;

Fcalculado = Valor calculado de F;

$M Q=$ Média quadrada;

F0,05 = Valor tabelado de f para o nível de significância de 5\%; e

$\mathrm{S}=$ Significativo / NS = Não significativo.

Tabela 15 - Resultados da ANOVA do índice de vazios dos concretos produzidos

\begin{tabular}{cccccc}
\hline Fator & GDL & MQ & Fcalculado & F0,05 & Significância \\
\hline A - Teor & 2 & 0,051667 & 1,43077 & 4,26 & NS \\
B - a/c & 2 & 0,701667 & 19,43077 & 4,26 & S \\
AB & 4 & 0,588333 & 16,29231 & 3,63 & S \\
Erro & 9 & 0,036111 & - & - & - \\
\hline
\end{tabular}

Nota: Legenda:

$\mathrm{GDL}=$ Graus de liberdade;

Fcalculado = Valor calculado de F;

$M Q=$ Média quadrada;

F0,05 = Valor tabelado de f para o nível de significância de 5\%;

$\mathrm{S}=$ Significativo; e

NS = Não significativo.

\section{Absorção por sucção capilar}

São apresentados na Figura 8 os gráficos de ganho de massa, em função da raiz quadrada do tempo, para os CPs ensaiados.
Com os gráficos de ganho de massa, em função da raiz quadrada do tempo, calcularam-se a absorção capilar e a resistência capilar, cujos resultados estão apresentados na Tabela 16. 


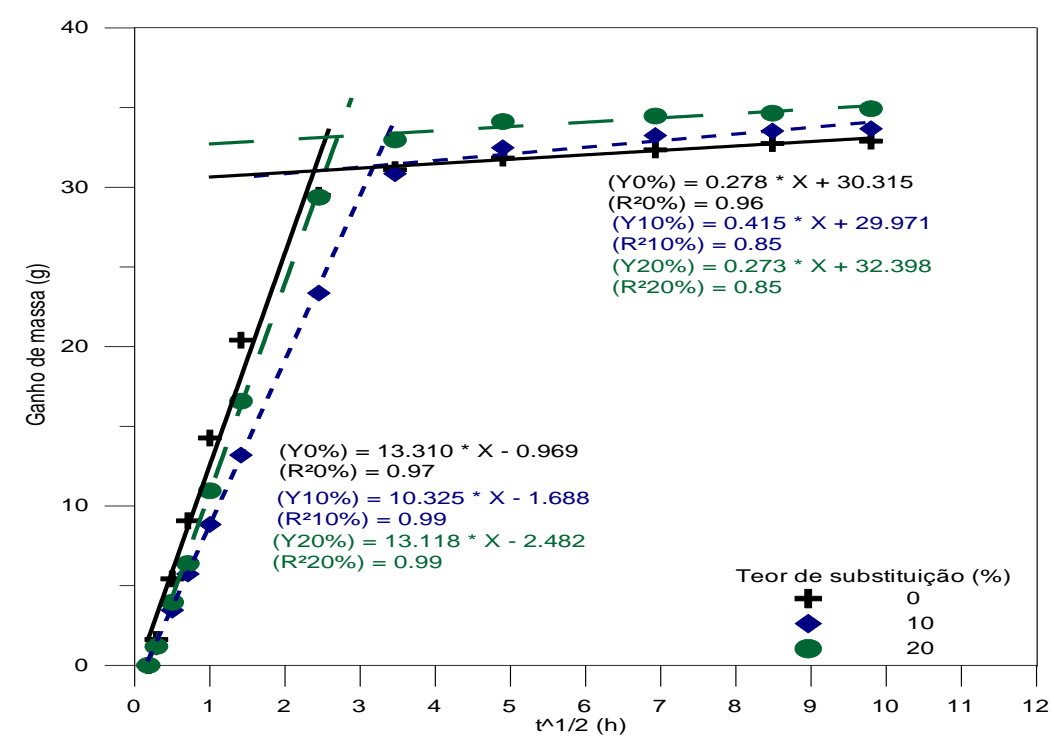

(a) $\mathrm{a} / \mathrm{c}=0,45$

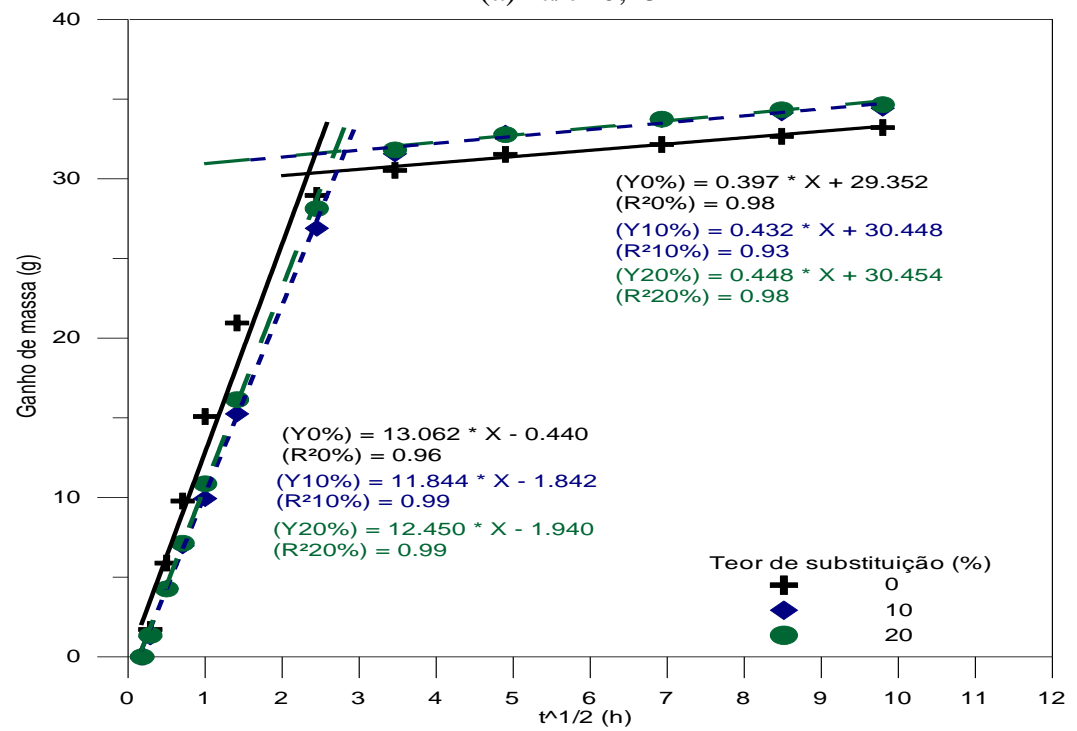

(b) $\mathrm{a} / \mathrm{c}=0,55$

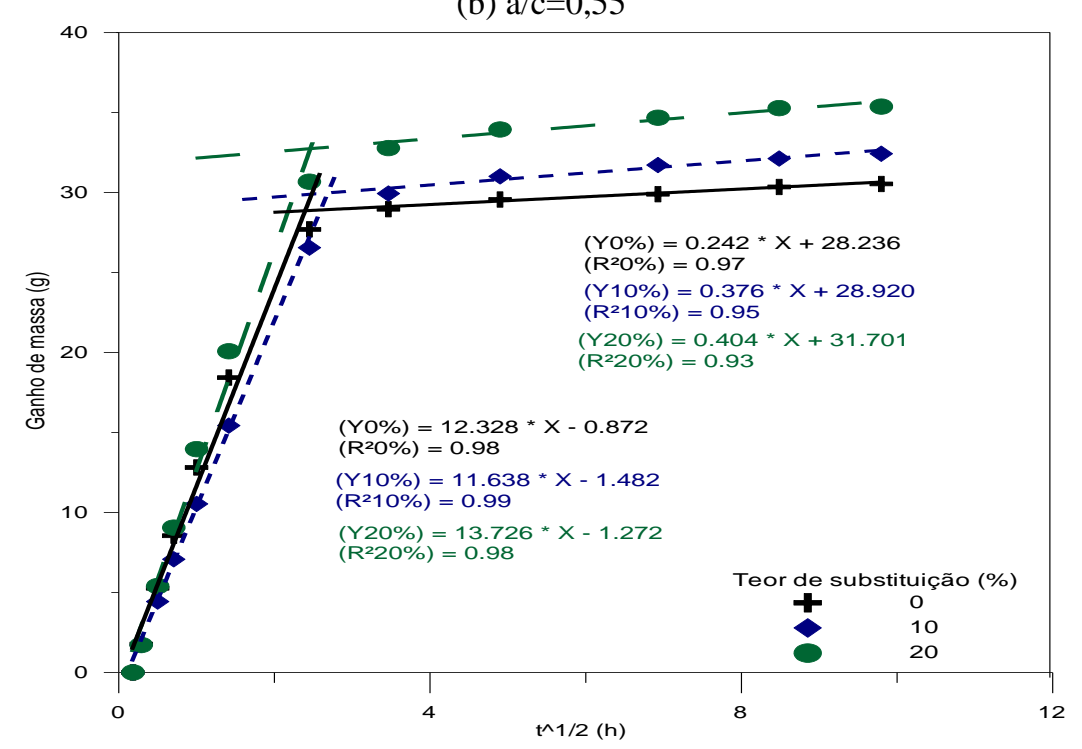

(c) $a / c=0,65$

Figura 8 - Ganho de massa dos concretos em função da raiz quadrada do tempo 
Tabela 16 - Resultados do ensaio de absorção por sucção capilar

\begin{tabular}{|c|c|c|c|c|c|}
\hline MISTURA & $\mathbf{a} / \mathbf{c}$ & $\begin{array}{c}\text { Absorção } \\
\text { Capilar } \\
\left(\mathrm{g} / \mathrm{h}^{\wedge} 1 / 2\right) \\
\end{array}$ & $\begin{array}{c}\text { Média da } \\
\text { Absorção Capilar } \\
\left(\mathrm{g} / \mathrm{h}^{\wedge} \mathbf{1 / 2}\right)\end{array}$ & $\begin{array}{c}\text { Resistência } \\
\text { Capilar } \\
\left(\mathbf{h} / \mathbf{m}^{2}\right)\end{array}$ & $\begin{array}{c}\text { Média da } \\
\text { Resistência } \\
\text { Capilar }\left(\mathbf{h} / \mathbf{m}^{2}\right) \\
\end{array}$ \\
\hline \multirow{3}{*}{ REF } & 0,45 & $\begin{array}{l}12,50 \\
13,29 \\
\end{array}$ & 12,90 & $\begin{array}{c}9.502 \\
11.168 \\
\end{array}$ & 10.335 \\
\hline & 0,55 & $\begin{array}{l}11,82 \\
13,72\end{array}$ & 12,77 & $\begin{array}{c}9.596 \\
10.266 \\
\end{array}$ & 9.931 \\
\hline & 0,65 & $\begin{array}{l}12,02 \\
11,90 \\
\end{array}$ & 11,96 & $\begin{array}{l}10.432 \\
10.169 \\
\end{array}$ & 10.300 \\
\hline \multirow{3}{*}{$10 \% \mathrm{RSPC}$} & 0,45 & $\begin{array}{c}9,41 \\
10,18\end{array}$ & 9,79 & $\begin{array}{l}15.744 \\
15.752\end{array}$ & 15.748 \\
\hline & 0,55 & $\begin{array}{l}10,57 \\
11,80\end{array}$ & 11,19 & $\begin{array}{l}12.955 \\
13.887\end{array}$ & 13.421 \\
\hline & 0,65 & $\begin{array}{l}10,60 \\
11,57\end{array}$ & 11,08 & $\begin{array}{l}12.979 \\
12.055\end{array}$ & 12.517 \\
\hline \multirow{3}{*}{$20 \% \mathrm{RSPC}$} & 0,45 & $\begin{array}{l}12,55 \\
11,86\end{array}$ & 12,20 & $\begin{array}{l}10.956 \\
11.630\end{array}$ & 11.293 \\
\hline & 0,55 & $\begin{array}{c}11,73 \\
(*)\end{array}$ & 11,73 & $\begin{array}{c}11.664 \\
---- \\
\end{array}$ & 11.664 \\
\hline & 0,65 & $\begin{array}{l}14,14 \\
12,28\end{array}$ & 13,21 & $\begin{array}{l}10.681 \\
11.612 \\
\end{array}$ & 11.146 \\
\hline
\end{tabular}

Nota: * o corpo de prova apresentou problemas, o que inviabilizou seu ensaio.

Na Tabela 17 são apresentados os resultados da ANOVA, mostrando que existe influência significativa do fator isolado teor de substituição sobre a absorção capilar dos concretos. Esse efeito pode ser verificado no gráfico da Figura 9.

Observou-se que os concretos com RSPC em substituição ao cimento apresentaram menor absorção capilar para todas as relações a/c estudadas, exceto para o concreto com $20 \%$ de RSPC, para relação a/c de 0,65, que proporcionou um aumento de $10 \%$ na absorção. Por outro lado, a resistência capilar dos concretos com RSPC foi maior para todos os teores e relações $\mathrm{a} / \mathrm{c}$ estudados. Pode-se atribuir esse comportamento ao efeito fíler proporcionado pelo resíduo, que estabelece uma barreira física à ascensão da água.

\section{Conclusões}

O resíduo de serragem de pedra Cariri (RSPC) apresenta estrutura tipicamente cristalina, com diâmetro médio dos grãos de 5,23 $\mu \mathrm{m}$. Portanto, o resíduo pode contribuir com o efeito fíler nos concretos.

A utilização do RSPC como substituição do cimento influenciou significativamente nas propriedades mecânicas dos concretos.

A resistência à compressão axial foi reduzida quando se utilizou RSPC. Com base nos resultados de 28 dias, pode-se observar que, quanto maior for o teor de substituição de cimento por RSPC, maior será a perda de resistência à compressão axial.

A resistência à tração por compressão diametral foi igual para todos os concretos com relação $\mathrm{a} / \mathrm{c}=0,55$, e praticamente igual para os concretos com relação $a / c=0,65$. Nos concretos com relação $\mathrm{a} / \mathrm{c}=0,45$, a utilização de RSPC, para todos os teores de substituição utilizados, proporcionou redução na resistência à tração por compressão diametral.

No que se refere aos parâmetros de durabilidade (absorção e índice de vazios), os concretos com a utilização de RSPC apresentaram comportamento compatível com os concretos de referência.

Considerando o conjunto de propriedades estudadas, não é tecnicamente recomendável a utilização de RSPC como substituição do cimento para os teores estudados. Entretanto, há de se considerarem as vantagens do ponto de vista ambiental, decorrentes da reciclagem do resíduo, considerando ainda que os concretos com RSPC apresentam desempenho compatível ao dos concretos de referência quanto às características relacionadas à durabilidade. Nesse sentido, é recomendável que seja realizada a avaliação do desempenho de concretos com teor de substituição de $5 \%$ de cimento por RSPC, de modo a verificar a viabilidade técnica da aplicação do resíduo na produção de concretos.

Tabela 17 - Resultados da ANOVA da absorção capilar dos concretos produzidos 


\begin{tabular}{cccccc}
\hline Fator & GDL & MQ & Fcalculado & F0,05 & Significância \\
\hline $\mathrm{A}-$ Teor & 2 & 6,114085 & 8,710376 & 4,26 & $\mathrm{~S}$ \\
$\mathrm{~B}-\mathrm{a} / \mathrm{c}$ & 2 &, 310467 & 0,442304 & 4,26 & NS \\
$\mathrm{AB}$ & 4 & 1,115986 & 1,589880 & 3,63 & NS \\
Erro & 9 & 0,701931 & - & - & - \\
\hline
\end{tabular}

Nota: Legenda:

$\mathrm{GDL}=$ Graus de liberdade;

Fcalculado = Valor calculado de F;

$M Q$ = Média quadrada;

F0,05 = Valor tabelado de f para o nível de significância de 5\%;

$\mathrm{S}=$ Significativo; $\mathrm{e}$

NS = Não significativo.

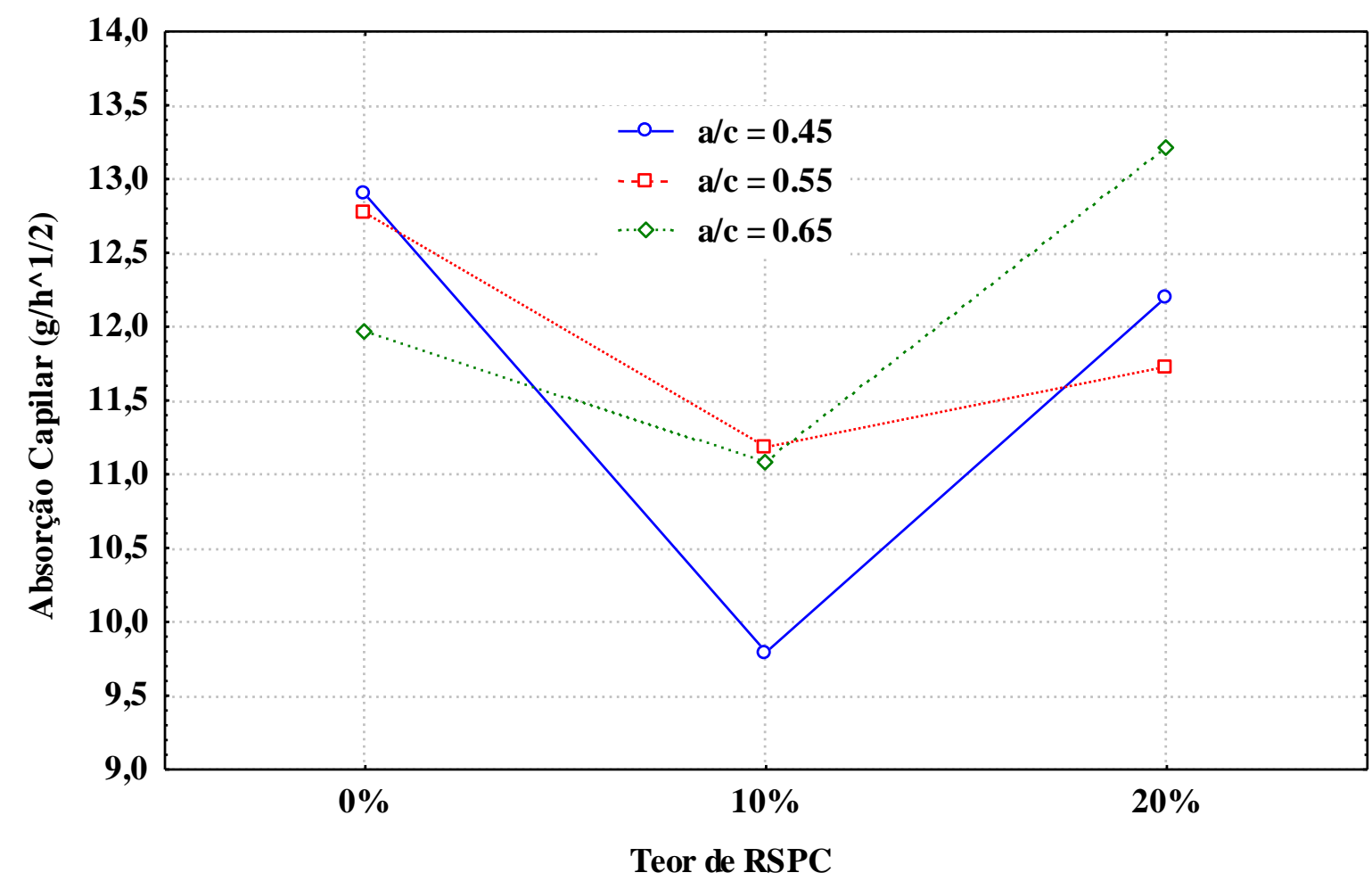

Figura 9 - Comportamento dos concretos quanto à absorção capilar

\section{Referências}

ALMEIDA, N. et al. High-Performance Concrete With Recycled Stone Slurry. Cement and

Concrete Research, v. 37, n. 2, p. 210-220, 2007.

ASSOCIAÇÃO BRASILEIRA DE NORMAS

TÉCNICAS. NBR 5739: concreto : ensaio de compressão de corpos-de-prova cilíndricos. Rio de Janeiro, 2007.

ASSOCIAÇÃO BRASILEIRA DE NORMAS TÉCNICAS. NBR 7222: argamassa e concreto: ensaio de resistência à tração por compressão diametral. Rio de Janeiro, 1994.

\section{ASSOCIAÇÃO BRASILEIRA DE NORMAS}

TÉCNICAS. NBR 9778: argamassa e concretos endurecidos: determinação da absorção de água por imersão: índice de vazios e massa específica. Rio de Janeiro, 2005.

\section{ASSOCIAÇÃO BRASILEIRA DE NORMAS}

TÉCNICAS. NBR 10007: amostragem de resíduos sólidos. Rio de Janeiro, 2004.

\section{ASSOCIAÇÃO BRASILEIRA DE NORMAS} TÉCNICAS. NBR NM 67: concreto:

determinação da consistência pelo abatimento do tronco de cone. Rio de Janeiro, 1998. 
ASSOCIAÇÃO BRASILEIRA DE NORMAS TÉCNICAS. NBR 5752: materiais pozolânicos: determinação de atividade pozolânico com cimento Portland. Rio de Janeiro, 1992.

CASTRO, N. F. Planejamento e Ordenamento das Atividades de Mineração de Calcários no Arranjo Produtivo Local do Cariri - CE. Rio de Janeiro, 2009. Dissertação (Mestrado em Engenharia Civil) - Instituto Alberto Luiz Coimbra de Pós-Graduação e Oesquisa de Engenharia, Universidade Federal do Rio de Janeiro, Rio de Janeiro, 2009.

CORINALDESI, V.; MORICONE, G.; NAIK, T. R. Characterization of Marble Powder For Its Use in Mortar and Concrete. Construction and Building Materials, v. 24, n. 1, p. 113-117, 2010.

CRUZ, D. F. M.; LAMEIRAS, R. M. Estudo das Propriedades Mecânicas de Argamassas Produzidas Utilizando-se Resíduo do Corte de Mármore e Granito. In: SEMINÁRIO DESENVOLVIMENTO SUSTENTÁVEL E A RECICLAGEM NA CONSTRUÇÃO CIVIL, 6., São Paulo, 2003. Anais... São Paulo, 2003.

ERGUN, A. Effects of the Usage of Diatomite and Waste Marble Powder as Partial Replacement of Cement on the Mechanical Properties of Concrete. Construction and Building Materials, v. 25, n. 2, p. 806-812, 2011.

GONÇALVES, J. P. Utilização do Resíduo de Corte de Granito (RCG) Como Adição Para Produção de Concretos. 135 f. Porto Alegre, 2000. Dissertação (Mestrado em Engenharia) Programa de Pós-Graduação em Engenharia Civil, Universidade Federal do Rio Grande do Sul, Porto Alegre, 2000.

GONÇALVES, J. P.; MOURA, W. A.; LEITE, M. B. Utilização de Resíduos Sólidos Industriais e Urbanos Para Produção de Concretos.

Engenharia, Ciência e Tecnologia, v. 6, n. 3, p. 17-30, maio/jun. 2003.

GOPALAN, M. K. Sorpivity of Fly Ash Concretes. Cement and Concrete Research, v. 26, n. 8, p. 1189-1197, 1996.

GJORV, O. Important Test Methods For Evaluation of Reinforced Concrete Durability. In: SYPOSIUM ON CONCRETE TECHNOLOGY: PAST, PRESENT AND FUTURE, Berkeley, 1993. Proceedings... Detroit: American Concrete Institute, 1994.

HELENE, P. R. L.; TERZIAN, P. Manual de Dosagem e Controle de Concreto. São Paulo: Pini, 1992.
JOHN, V. M. Reciclagem de Resíduos Sólidos na Construção Civil: contribuição à metodologia de pesquisa e desenvolvimento. 102 f. São Paulo, 2000. Tese (livre docência) - Escola de Engenharia, Universidade de São Paulo, São Paulo, 2000.

KELHAM, S. A. Water Absorption Test For Concrete. Magazine of Concrete Research, v. 40, n. 10, p. 106-110, jun. 1988.

LAMEIRAS, R. M. Desenvolvimento de Concretos Através da Utilização do Resíduo do Beneficiamento de Chapas de Granito (RBCG). Maceió, UFAL, 2004.

MOURA, W. A. Utilização de Escória de Cobre Como Adição e Como Agregado Miúdo Para Concreto. 192 f. Porto Alegre, 2000. Tese (Doutorado em Engenharia Civil) - Escola de Engenharia, Universidade Federal do Rio Grande do Sul, Porto Alegre, 2000.

MOURA, W. A.; GONÇALVES, J. P.; LEITE, R. S. Utilização do Resíduo de Corte de Mármore e Granito em Argamassas de Revestimento e Confecção de Lajotas Para Piso. Sitientibus, Feira de Santana, v. 26, n. 1, p. 49-61, jan./jun. 2002.

NEVES, G.A. Reciclagem de Resíduos da Serragem de Granitos Para Uso Como MatériaPrima Cerâmica. 242 f. Campina Grande, 2002. Tese (Doutorado em Engenharia Civil) - Curso de Pós-Graduação em Engenharia de Processos, Universidade Federal de Campina Grande, Campina Grande, 2002.

SILVA, A. D. A. et al. Aproveitamento de rejeito de calcário do Cariri cearense na formulação de argamassa. Estudos Geológicos, v. 18, n. 1, 2008.

TENÓRIO, J. J. L. Desenvolvimento de Argamassa Através da Utilização do Resíduo do Beneficiamento de Chapas de Granito (RBCG). 62 f. Maceió, 2004. Monografia (Trabalho de Coclusão de Curso) - Curso de Graduação em Engenharia Civil, Universidade Federal de Alagoas, Maceió, 2004.

VIDAL, F. W. H.; FERNANDES, T. W. G. Inovação tecnológica para valorização da pedra Cariri - CE. In: CONGRESSO BRASILEIRO DE ROCHAS ORNAMENTAIS, 3, SIMPÓSIO DE ROCHAS ORNAMENTAIS DO NORDESTE, 6 , Rio de Janeiro, 2007. Anais... Rio de Janeiro: CETEM/MCT, 2008. p. 298-305. 


\section{Agradecimentos}

Os autores agradecem à Capes, pelo apoio financeiro, ao Laboratório de Tecnologia da UEFS (LABOTEC), ao LABEST, da COPPE/UFRJ, e à Coopedras, na pessoa do Sr. Gerlândio, pelo fornecimento e transporte do RSPC.

Revista Ambiente Construído

Associação Nacional de Tecnologia do Ambiente Construído

Av. Osvaldo Aranha, $99-3^{\circ}$ andar, Centro

Porto Alegre - RS - Brasil

CEP $90035-190$

Telefone: +55 (51) 3308-4084

Fax: +55 (51) 3308-4054

www.seer.ufrgs.br/ambienteconstruido

E-mail: ambienteconstruido@ufrgs.br

24 Moura, W. A.; Leite, M. B.; Bastos, A. J. O. 